In H. Joffe, T. Rossetto \& J. Adams (Eds.). (2013). Cities at risk: Living with perils in the $21^{\text {st }}$ Century. Springer

\title{
RISK SOCIETY AND REPRESENTATIONS OF RISKS: EARTHQUAKES AND BEYOND
}

\author{
Helene Joffe $^{1}$ \& Cliodhna O’Connor ${ }^{1}$
}

1) Division of Psychology \& Language Sciences, University College London

Email: h.joffe@ucl.ac.uk

\section{ABSTRACT}

This chapter explores how lay publics respond to potential disasters. It contends that the current risk perception field largely neglects the common-sense beliefs and emotions that lie at the root of public responses to risks. The chapter challenges several of the assumptions that buttress the conventional construal of the terms 'risk' and 'perception'. It proposes that the current focus on how the individual mind cognitively processes predictable, calculable phenomena should be replaced by emphasis on how emotional and socio-cultural beings represent often unknowable potential catastrophes. Social representations theory is put forward as a viable theoretical framework within which this shift could be achieved. The chapter illustrates the value of a social representations approach to studying risk by presenting the findings of a cross-cultural study examining social representations of earthquakes in cities at risk of earthquakes in the US, Japan and Turkey. The chapter concludes by proposing routes by which the findings of such studies could be channelled into behavioural intervention programmes.

\section{INTRODUCTION}

This chapter examines how members of the public represent potential catastrophes, from earthquakes to pandemics. It offers a challenge to the 'risk perception' research agenda as well as to the conventional construal of both of the terms 'risk' and 'perception', en route to proposing core emotional and socio-cultural drivers that shape how people face the dangers and catastrophes of the future. In doing so, it complements and extends existing work on how people think, feel and act in relation to the host of dangers that they face.

\section{Challenging the term 'risk'}

The contemporary definition of risk used by experts relates to predicting the "probability of an event, combined with the magnitude of losses and gains that it 
will entail” (Douglas, 1992, p. 40). In the safety sphere the 'gains' element tends to drop away and 'risk' represents the risk of death, but also the risk of disfigurement or disability. Thus, regarding the perils of the future, risk can simply be defined as the probability that a harmful event will occur (Weinstein, 2003).

The emphasis on probability calculation demonstrates that this understanding of risk represents a very different orientation to peril from that which existed in pre-modern times (Bernstein, 1998). In the anthropologist Mary Douglas' accounts of pre-modern societies, risk simply means 'danger from future damage', with a community's construal of the dangers they face intimately linked to local cultural operations of morality, responsibility attribution and intergroup boundaries (Douglas, 1992; Douglas \& Wildavsky, 1982). In contrast, contemporary usage of the term 'risk' implies precision of calculation, objectivity and control (Joffe, 1999). Viewing dangers in terms of causal, predictable relations is a distinctively modern phenomenon, swathing dangers in an aura of scientific measurement and control (Bernstein, 1998; Douglas, 1992).

Undoubtedly, modern scientific and technological advances have indeed increased the extent to which human society can control many dangers. A host of the diseases that blighted previous eras, for example, have been rendered harmless due to use of antibiotics and vaccination programmes. However, a key dimension of risk in contemporary society is that the very interventions implemented to manage risks can set off unknowable chain reactions that generate further perils that elude human control. The emergence of new antibiotic-resistant strains of bacteria due to antibiotic overuse is a case in point. This observation buttresses the contention of sociologist Ulrich Beck $(1992 ; 2006)$ that the sense of control over perils that is implied by the contemporary construal of 'risk' is largely illusory and ironic. Beck terms our late modern society 'risk society' (Beck, 1992), or more latterly 'world risk society' (Beck, 2006), a phrase that “describes a phase of development of modern society in which the social, political, ecological and individual risks created by the momentum of innovation increasingly elude the control and protective institutions of industrial society” (Beck, 1996, p. 27).

Beck postulates that contemporary society is characterised by a profusion of fundamentally incalculable risks and that within the risk society, highly developed institutions (most notably science) try to anticipate what cannot be anticipated. Beck illustrates this irony with the following example: "when suicide terrorists succeeded in turning commercial passenger aircraft into rockets, which destroyed symbols of American world power" this was "an action that was utterly improbable according to every logic of risk” (Beck, 2006, p. 330). The irony here, in terms of the science of predicting risk, is that past experience encouraged anticipation of the wrong type of risk: before September 11, 2001, the World Trade Centre had been the target of a terrorist truck bomb, making camera surveillance widespread, but not regarding a potential air attack. This instance of relying on histori- 
cal risk patterns to foretell those of the future stands as a sobering example for those working within the field.

A more recent manifestation of the unpredictable nature of danger lay in the unanticipated outbreak of widespread Swine Influenza (H1N1) between the summer of 2009 and autumn of 2010, which arose in place of a predicted Highly Pathogenic Avian Influenza (HPAI) pandemic. One might argue that the World Health Organisation's (WHO) declaration of (what turned out to be) a relatively mild bout of Swine Influenza as a pandemic owed more to its historical links with the 1918 'Spanish Flu' (which may have contained strains of the same H1N1 virus) and the anticipation of severe strains of Highly Pathogenic Avian Influenza than to the outbreak itself. Extensive preparations had been made for HPAI, including efforts by the WHO and UNICEF to devise programmes for drug and vaccine supply as well as public education and engagement activities (Scoones \& Foster, 2010). These plans were quickly adopted as the basis for managing the unexpected H1N1 outbreak, with the result that the major international effort to produce and distribute anti-retrovirals and vaccinations was directed at a more severe level of risk than that which arose. The science of predicting risk can therefore prove an unreliable guide for risk management decisions, causing scientific and financial resources to be channelled into activities that are wide of the mark.

A final example of past experience encouraging anticipation of the wrong type of risk relates to the devastation that followed the March 2011 earthquake and tsunami in Tōhoku, Japan. For economic reasons, most countries choose not to produce building codes and structures that anticipate the most extreme seismic scenarios (and consequently are most costly). Rather, authorities determine the levels of structural resilience that buildings must conform to based on what are considered to be the most likely upper limits of future earthquakes and tsunami. These calculations are made on the basis of the seismic history of the area. On the basis of probabilistic assessments of the hazard in each location, which take into account earthquake magnitude over previous centuries, engineers had prepared structures (in terms of building codes and coastal defences) to withstand earthquakes of a magnitude between 7 and 8 (see Nishikawa, 2011), and their equivalent tsunami. Disastrously, the earthquake that hit Tōhoku on March 11, 2011 measured magnitude 9 and, together with its incipient tsunami, destroyed villages, damaged several nuclear reactors and caused the deaths of approximately 16,000 people, with a further 3,000 recorded as missing (World Health Organisation, 2012). Preparing solely for the statistically probable can therefore produce catastrophic results.

These three examples indicate that far from being foreseeable and calculable phenomena, many future dangers are unknown and unknowable. Complex, long 
return period ${ }^{1}$, spatially variable dangers - ranging from earthquakes to pandemics to climate change - often cannot be accurately predicted. Those prediction efforts that are nevertheless mounted may not produce very useful information: subject to numerous sources of error and variation, they are at best merely "pieces of an intricate puzzle that may sometimes contribute to improved decisions" (Sarewitz, 2010, p. 24). The gradual devaluation of prediction is vividly illustrated in the historical evolution of the field of seismology, which has (rather uniquely among scientific fields) decisively shifted its focus away from prediction towards building resilience in the face of vulnerability (Hough, 2010; Sarewitz, 2010). Indeed, earthquake prediction is now a stigmatised pursuit among seismologists (Joffe, Rossetto, Bradley \& O’Connor, submitted). Sarewitz (2010) states that the climate change area should, similarly, aspire to decreasing people's vulnerability rather than to prediction, if the catastrophe is to be allayed. Thus, the validity and even desirability of treating risks as predictable, calculable phenomena is challenged by researchers, practitioners and theorists in certain fields.

\section{Challenging the term risk 'perception'}

Beck's risk society theory effectively critiques the often inflated confidence of scientific fields in their powers of calculability. Once 'risks' are reframed as partly unknowable dangers or perils, rather than predictable, calculable entities, this chapter argues that we need a better model of what members of the public do with the unknowable than we currently see in the 'risk perception' field. The term 'perception' generally pertains to sensorial knowledge - how one's senses register a particular entity. Since the 1950s, the study of risk perception has been dominated by the field of cognitive psychology, which generally approaches risk perception as a form of 'information processing', focusing on the internal cognitive processes that occur when laypeople are confronted with risk.

In recent times, the validity of conceptualising risk perception solely in terms of individual cognition has been questioned. One particularly salient basis for critique argues that treating responses to risk as mechanical information-processing that occurs within the individual mind obscures the inter-subjective aspects of knowledge (Joffe, 2003). People do not navigate the world as atomised individuals, but rather are embedded in social groups, cultures and societies. When confronted with risks, people draw on the meaning systems and ways of thinking associated with the groups to which they belong; responses to risks develop in and through interaction with other social actors (Kahan, Jenkins-Smith \& Braman, 2010; Joffe, 2003). In contemporary society, risks are generally 'perceived' not via direct sensory information, but via media reports heralding news of an imminent danger. Such reports often relay scientifically-generated information in a

${ }^{1}$ The term 'return period' refers to the average intervals of time between hazard events such as floods or earthquakes. 
more populist form, for example, sensationalised media coverage of emerging infectious diseases (Joffe \& Haarhoff, 2002; Washer, 2004; 2006; Washer \& Joffe, 2006; Washer, Joffe \& Solberg, 2008). The formation of 'risk perception' does not involve independent observation of stable external objects, but rather handling an intricate mix of visual and textual information that is communicated by a host of other social agents and institutions. Thus, what is termed 'perception' is a complex process involving engagement with sets of images and words that circulate in society and that may re-iterate and re-interpret 'official' risk information. Focusing one's lens purely on the individual mind means that the constitutive influence of such social phenomena remains unexplored.

A further area that remains largely untapped by conventional understandings of risk perception relates to the emotional dimension of responses to risk (for exceptions see Lerner, Gonzalez, Small \& Fischhoff, 2003; Peters, Burraston \& Mertz, 2004; Sjoberg, 2007). Risk perception is often characterised as defined by rather 'cold' cognitive variables, such as estimated likelihood of being affected by the threat, perceived efficacy in relation to it and perceived severity of the risk. While research on such variables has undoubtedly furnished useful results, an exclusive focus on the pathways of rational thought involved in risk responses is misguided. A refrain throughout this chapter will be that rather than the more rational, cognitive processes currently given prominence, a more emotive dimension lies at the core of the response to danger. This is not to say that the former is not involved: dual-process theories suggest that 'thought' might comprise both a rapid, emotional dimension and a stream devoted to slower, more deliberative cognitive processing (Epstein, 1994). In recent times, dual-process theories have increasingly found voice in the work of psychologists working on risk perception, who conceive of responses to potential dangers as operating along rapid 'feeling' and slower 'analysis' dimensions (Slovic, Finucane, Peters \& MacGregor, 2004; Slovic \& Peters, 2006). Key theorists of the 'risk perception' model are now redressing the relegation of emotion in giving primacy to 'the feeling of risk', as is the title of Slovic's (2010) more recent anthology, in contrast to his earlier 'The perception of risk' (2000). However, it must be noted that the 'risk as feeling' trend within the psychology of risk perception devolves largely around 'affect', which Slovic et al. (2005) define as a 'faint whisper of emotion' (p.353) demarcating the goodness of badness of a stimulus. Affect is experienced as a feeling, either consciously or non-consciously and demarcates a positive or negative aspect of the stimulus. Slovic et al. state that the more 'visceral emotion of fear' that people may experience regarding the potential danger is not what is being referred to. Much of Leiserowitz's work (e.g. Leiserowitz, 2006; Smith \& Leiserowitz, 2012) on perceptions of climate change affect typifies this trend. In addition, the psychology that finds its way into other fields and applied contexts often remains mired in older models of risk perception with their highly cognitivist, rational focus on probability assessment. 
A further difficulty with the way in which risk perception research has been pursued lies in the somewhat dismissive orientation it adopts to lay knowledge. Much risk 'perception' research could more accurately be characterised as research on risk 'misperception'. The risk perception research agenda often invokes the notion of a fundamental division between the knowledge held by experts, which is assumed to be objective, correct and authoritative, and that held by laypeople, which is subjective, irrational and often erroneous. Scientific evaluations of risks, from food scares to climate change to natural disasters, are rarely wholly unanimous or immutable; Beck (2006) contends that it is scientists whose "findings often contradict each other, who change their minds so fundamentally that what was judged 'safe' to swallow today, may be a 'cancer risk' in two years' time.” (p. 345). Indeed, fallibility is a cornerstone of scientific method and philosophy. Despite this, it is laypeople whose (mis)judgements and biases are emphasised, with deviations between lay beliefs and current expert consensus invariably attributed to errors on the part of the lay thinker. In particular, the risk perception field examines the numerical probabilities people offer in estimating their chances of being affected by a particular risk. These are then compared to scientific estimates to identify how the public distort risk information, typified in the frequent laments about the public's amplification of certain hazards that experts deem low-risk such as air travel, and underestimation of those, including car travel, which they 'should' rate as high risk.

The focus of the risk perception field on perceptual and cognitive error in apprehending expert-defined risks often implicitly endorses a 'deficit model' of public responses to scientific information. The deficit model approach to lay knowledge assumes that the public are ignorant of scientific 'facts' and seeks to rectify what is seen as an information- or knowledge-gap between science and its lay recipients (Hilgartner, 1990). Deficit model approaches have been criticised both for reifying expert perspectives as objective truth and for propagating a view of a single, context-independent rationality, thereby precluding recognition of alternative forms of rationality that operate within local contexts. For example, Graham's (1993) study of attitudes to smoking risk among socio-economically disadvantaged single mothers showed that women were aware of smoking's health risks, but consciously judged that these were outweighed by the benefits they derived from smoking, in providing a form of stress relief in harsh social circumstances. Risk evaluations that deviate from expert advice are therefore not necessarily irrational or uninformed, but rather can reflect the contingencies people live with. Within theorisation of science's role in society, the deficit model has now fallen from favour, with a focus on public 'understanding' of science shifting to public 'engagement' with science (Bauer, 2009). The shift to public engagement with science leaves open alternative ways of theorising public responses to risk, which do not privilege one particular form of thinking and that examine the texture and consequences of lay thought without an agenda of judging whether it is 'right' or 'wrong'. 


\section{Evidence for 'risk perception' driving action?}

A key ambition of those who use risk perception research in applied contexts is the development of effective means of predicting (and, it is hoped, thereby understanding and changing) people's risk-related behaviour. Thus a question arises concerning its explanatory power in the area of behaviour: are people's dangerrelated behaviours driven by the cognitive components of responses to danger, or by other elements that are based in the emotional and socio-cultural experience of risk?

Efforts to change people's risk behaviour have traditionally relied on 'public education' campaigns, assuming that if people are aware of a risk and know what to do, they are likely to act accordingly. This assumption is rooted in the rationalist philosophy that has dominated the psychology of risk since the mid-twentieth century, typified in the names of prominent models of the thought-action relationship such as the 'Theory of Reasoned Action' and 'Theory of Planned Behaviour' (Ajzen, 1991; Fishbein \& Ajzen, 1975). The limits of rationalist understandings of risk-related behaviour have gradually become evident (see Joffe, 1996). In the area of adjusting to earthquake threat, for example, research generally concludes that awareness of earthquake risk and some of the variables contained in the cognitive models are only weakly related to undertaking protective behaviour (Solberg, Rossetto \& Joffe, 2010). Solberg et al.’s (2010) review highlights the importance of factors with emotional and/or socio-cultural foundations, such as trust, social identity, attributions of responsibility and fatalism in informing earthquake preparedness. Extensive research in the area of emerging infectious diseases has also corroborated the importance of trust and the emotional experience of worry in influencing the actions people take to reduce their risk of infection (Bish \& Michie, 2010; Rubin, Potts \& Michie, 2010). Buttressed by such findings, recognition of the limits of purely cognitive approaches appears to be dissipating further into the risk perception field: Twenty-five years after research began on the notion of 'optimistic bias' (Weinstein, 1978), a 'cognitive distortion' whereby people see themselves as less vulnerable to dangers than their peers, the psychologist who pioneered the concept has begun to change his take on what drives behaviour, shifting from the purely cognitive to the more emotive realm: "considerable evidence exists demonstrating that worry (a poorly defined concept containing elements of both emotion and attention) [...] provides predictive power beyond that provided by judgements of likelihood and severity" (Weinstein, 2003, p. 48). Indeed, the very phenomenon of optimistic bias may be fundamentally emotionally driven, reflecting a defensive response to fear rather than 'cold' cognitive error (Joffe, 1999).

Thus, it seems that faulty judgements are not the key or sole predictors of people's responses to risks. With an understanding of 'risk' as 'potential danger' 
(Douglas, 1992), or as Beck (2006) puts it, ‘anticipated catastrophe’, what comes to the fore is emotion in relation to threat. Theorists such as Beck suggest that from a technical perspective, part of the work of modernity is to set in motion mechanisms to control the incalculable and unknowable - from vaccination to early detection systems, from retrofitting to the science of risk perception. This machinery of control does not always function as intended or desired, and humans must develop other means of managing the emotional challenges that arise in times of crisis.

\section{A more fitting theory of people's apprehension of dangers: from 'risk per- ception' to 'risk representation'}

When a focus on the accuracy of public 'understandings' or 'perceptions' of risks is replaced by a concern with public 'engagement' with potential dangers, respect for local knowledge becomes central. This chapter posits a theory that takes as its subject the common-sense of local knowledge: social representations theory (SRT), a social psychological theory that examines lay uptake of societal phenomena (Moscovici, 1961/2008). Social representations are widespread 'ensembles of thoughts and feelings' about a given phenomenon akin to a 'lay theory' or 'lay explanation'. This 'ensemble of thoughts and feelings' is expressed by individuals in their conversation, behaviour and internal understandings (Wagner et al., 1999) but underpinned by socio-cultural, historical and group-specific ideologies. Thus, with SRT the theoretical emphasis shifts from the individual mind as a processor of risk information to people and their ideas as products of their histories, social groups and cultures. Furthermore, the theory contends that people "generate representations not so much by a reasoning or computing process as by a process of communicating” (Moscovici, 1984, p. 951). This is particularly relevant to representations of risks such as earthquakes, climate change and flooding, which do not merely face individuals but neighbourhoods, communities and countries. Representations of these phenomena are forged in the ongoing communication that occurs between people, and a considerable portion of the representations of these threats is therefore socially shared. The aim of SRT is to document this shared portion of knowledge about particular phenomena. The foci thus become exploration of the substantive content of what people say about threats (as opposed to, for example, numerical probability estimates) and examination of widespread, culturally-based representations of the threat (as opposed to individual-level variables).

SRT holds that in the course of communication about a new risk, two processes occur: 'anchoring', by which existing ideas and concepts are imposed upon the new information, and 'objectification', where the new information is assimilated into people's knowledge by means of familiar symbols, metaphors and images. For example, Japanese mythology represents earthquakes as a consequence of the movement of giant catfish (Namazu) who live underground (Yamori, this volume). Official Japanese earthquake information communications today continue to re- 
cruit images of catfish: despite the catfish explanation of earthquakes not being literally believed, the historical symbol has persisted and effortlessly connotes 'earthquake' to Japanese people.

An important facet of the application of social representations theory to studying responses to risk relates to its incorporation of the emotive dimension of knowledge. For example, Höijer's (2010) analysis of coverage of climate change in Swedish newspapers pinpoints the importance of the emotions of fear, hope, guilt, compassion and nostalgia in constituting the social representations that evolve. Moscovici (1961/2008) suggests that social representations emerge in response to a threat to a group's identity or way of life, and that a central function of social representation is to defend against such threat by 'making the unfamiliar familiar'. Psychological efforts to manage emotions like anxiety can therefore shape the representations of risk that evolve. For example, Joffe's (1999) research documents how social representations of AIDS in the 1990s developed along a pattern of 'not me, the other is to blame', with a variety of different groups downgrading their own vulnerability to HIV/AIDS and focusing on the inflated risk they attributed to dissimilar 'others', such as gay men or people from other countries. This tendency to distance the self from worrying phenomena by projecting risk onto 'the other' permeates responses to a wide variety of risks, including a range of infectious diseases (Joffe, 2011), climate change (Smith \& Joffe, 2013) and earthquakes (Joffe et al., in press).

A strength of the social representations framework as a theory of public engagement lies in its ability to see different publics' accounts of a given danger as forms of knowledge in their own right rather than as deficient forms of scientific knowledge (Duveen, 2008). SRT examines the contents of people's risk-related thinking without reference to the 'reality' of the risk; the concern is not with the accuracy of the representation but with the meanings that people attach to a given risk and the consequences of these meanings for themselves, for others and for society. These 'common-sense' notions are no less important than people's more scientifically-informed knowledge in shaping their responses to the risks they encounter. On a practical note, this is an important consideration for policy makers seeking to understand how people's danger-related thinking 'works' and might therefore be challenged and changed: focusing purely on the accuracy of people's scientific knowledge means that other dimensions of their risk-related thought, feeling and behaviour remain undocumented. More naturalistic studies that focus on where people are rather than where they should be have clear advantages for developing interventions. As Fishbein and Cappella (2006, p. S4) state, "one must understand the behavior from the perspective of the population for whom the interventions are being developed. Once understood this way, these beliefs can serve as the basis for messages and other interventions”. A further advantage that SRT offers for policy concerns relates to its concentration on the communicative aspects of social representations. It interrogates the role played by messages that cir- 
culate in the public sphere, particularly within the mass media, in shaping risk representations (e.g. see Washer, Joffe \& Solberg, 2008). Such analyses can indicate how change can be effected in threat-related behaviour through changes in the communications people encounter.

To illustrate the usefulness of adopting a view of responses to risk as emotional and socio-cultural phenomena, this chapter introduces an empirical study of how people living in the cities of Seattle (USA), Izmir (Turkey) and Osaka (Japan) - all areas that are highly seismic but that have not recently been directly affected by damaging earthquakes - represent earthquakes.

A new way of studying responses to earthquake risk: The EPICentre risk representation project

Investigation of naturalistic representations of a given threat involves a departure from conventional psychological methods of experimentation and survey research. Survey and experimental methods require that a researcher predefine the variables of interest, leaving little space for the emergence of findings that have not been anticipated. This is particularly problematic when there is a cultural gap between the researcher and participant, as the cross-cultural equivalence of concepts cannot be assumed. Furthermore, surveys, in particular, tap only consciously available cognitions. If people's risk-related ideas are informed by values, images and emotions that are not necessarily conscious, this material will not become visible in self-reported questionnaire responses. An additional issue relates to the extent to which the psychological response to risk can be captured using purely quantitative measures, or whether important facets of the texture of thought are lost when it is translated into a series of numbers.

These concerns with the validity of conventional methods of investigating human responses to risk stimulated researchers working within UCL's Earthquake and People Interaction Centre (EPICentre) to develop a new research technique, combining features of free-association with qualitative interview methodology (Joffe, 2011; Joffe \& Elsey, under review). The method involves presenting participants with an empty four-box grid and asking them to write or draw the first four words, feelings or images that come to mind when exposed to a certain prompt - in this case, the word 'earthquake'. The researcher then conducts an interview that is structured around these free-associations, asking the respondent to expand upon the associations they produced and asking follow-up questions to prompt the respondent to elaborate further. The interviewer avoids posing questions about areas or ideas that have not been spontaneously volunteered by the respondent, thereby ensuring that the researcher's preconceptions have minimal influence on the material gathered. This provides a greater degree of confidence that the data reflect the individual's naturalistically-occurring thought patterns and tap the stored, automatic links made to the risk in question. Furthermore, free associa- 
tions reveal people's most salient associations to the phenomenon, which Hollway \& Jefferson (2000) suggest are primarily emotive. Thus the method provides an entry-point into the emotional substructure of people's responses to risk. The interviews are recorded, transcribed verbatim, and analysed using qualitative analytic procedures such as thematic analysis in order to identify any patterns in individuals' responses to the risk. The data that emerge from this method are distinctive in the extent to which they reveal latent emotional and socio-cultural drivers of responses to risk.

EPICentre's project involved a cross-cultural application of this method to interview demographically-matched samples of 48 individuals in each of three earthquake-prone cities - Seattle, Izmir and Osaka. The results of this study, presented in Joffe, Rossetto, Solberg and O’Connor (in press), contradict the conventional assumption that action to reduce one's risk results from perceiving a risk as likely and severe. Questionnaire data collected alongside the interviews (see Rossetto, Joffe \& Solberg, 2011) indicated that despite universally high awareness of earthquake threat, participants in all three cities did little to prepare for earthquakes or mitigate their risk. Out of a list of nineteen risk-reducing actions, participants in all locations reported having done (on average) less than half, though the Americans had adopted a significantly greater number of actions than either the Turkish or Japanese participants.

Qualitative analysis of the interview data threw light on people's failure to act to reduce their earthquake risk. Analysis indicated that important contributors towards whether people acted or not lay in their emotional responses to earthquake threat. While the Japanese and particularly the Turkish respondents associated earthquakes with intense panic, fear and anxiety, American respondents displayed a much more moderate level of concern. Indeed, positive emotional responses to earthquakes were not uncommon in the US sample, with earthquakes provoking emotions such as awe, exhilaration and fascination. The Turkish interviews were also notable for the intensity of emotions related to anger, blame and distrust of state and construction authorities, whose negligence and corruption were positioned as the cause of earthquake damage. While US and Japanese participants distanced themselves from threat by favourably comparing themselves to other places that they saw as subject to a greater earthquake risk, Turkish participants sharply demurred from this pattern: they also compared themselves with other countries, but with the outcome of reinforcing their sense that they themselves were extremely vulnerable to earthquake damage.

These emotional responses to earthquake threat interacted with a cluster of feelings relating to a sense of agency and control in relation to earthquakes. Almost all participants demonstrated at some point in the interview that they were aware that actions were available by which they could reduce their risk from earthquakes. However, alongside this awareness lay strong trends towards fatalism in all three 
cities, with respondents asserting that human action is pointless in the face of earthquake threat. These fatalistic tendencies were clearly culturally grounded and were rooted in different belief-systems in the three countries. US and Japanese fatalism largely followed from cultural representations of earthquakes as acts of nature, which is a sphere immune from human influence. The fatalism present in the Turkish data, on the other hand, drew more on a religious framing of earthquakes as acts of divine power, as well as an emphasis on vulnerability caused by institutional corruption.

Framing the failure to act within the emotional and socio-cultural contexts revealed in the interviews furnishes important insights into the risk experience of citizens of earthquake-prone cities. The data suggest that emotional and sociocultural variables exert an appreciable influence on people's risk-relevant behaviour. The intense emotions experienced by the Turkish and Japanese participants, in combination with cultural currents that represented earthquakes as insurmountable forces, seem to have overwhelmed people and paralysed them from action. The US participants displayed a more muted emotional response to earthquakes and also reported the greatest levels of protective action. A more moderate level of concern, rather than high anxiety, may be more facilitative of earthquakeprotective behaviour. Nevertheless, even the US participants performed less than half of the recommended practices, with action possibly undermined by cultural representations of earthquake threat as impervious to human action.

\section{Concluding comments}

This chapter has polarised the more cognitive as opposed to the more emotive and cultural approaches to public engagement with risks. It has leant towards championing the latter since this rectifies an imbalance in the literature. However, the facets work in tandem. The method adopted in the EPICentre project provides the groundwork for establishing a valid model for risk-related thought, feeling and ultimately behaviour. Beyond its qualitative exploration of free associations, it also explored some of the more traditional variables found in 'risk perception' studies to gain a holistic picture of how people engaged with earthquake risk.

When 'risk perception' is approached in this way, we see that the public's assessments of potential dangers do not differ from those of experts purely because they cannot do the sums. Rather, they care about different things: people's representations of risk are not solely based on evaluations of probability and severity, but incorporate a wide range of relevant information about the personal, community and societal contexts in which the disaster would occur. Izmir's residents' failure to act is not a consequence of ignorance or inaccurate judgement, for example, but of their representation of the structures they live in as badly built. High levels of structural vulnerability are represented as resulting from corruption in the building industry and among those who (fail to) regulate it. The sense of living in 
unsafe structures undermines people's self-efficacy as they feel that their actions will be pointless since their buildings are not correctly built to withstand earthquakes. Decision not to devote resources to such activities is understandable in this light. The shift from traditional 'risk perception' to 'representations of potential catastrophes' acknowledges the contextual and multi-faceted nature of lay knowledge, and examines it on its own terms without an agenda of determining whether it is deficient or adequate with reference to an ideal 'expert' position.

This respectful orientation to lay knowledge provides a clear advantage when incorporating research into policy implementation or behaviour change programmes. Though methodologically convenient, squeezing lay experience into a form that it does not take naturalistically means that resultant policy initiatives draw on a contorted picture of ordinary thought and behaviour, leaving their implementation vulnerable to unanticipated reactions. Since a social representations approach starts with where people are rather than where they 'should' be, thereby furnishing a valid and comprehensive depiction of lay experience, this map of the contours of social life can be used by policy initiatives to plan an implementation strategy that promotes public engagement and support.

The EPICentre study provides a counter-balance to predominantly cognitive perspectives on risk perception. Social representations are highly dynamic: they are "networks of interacting concepts and images whose contents evolve continuously over time and space" (Moscovici, 1988, p. 220). The concept of social representation thus contains within it the propensity for change. SRT's focus on the dependence of internal representation on the external socio-cultural environment brings to the fore the role played by the media and other societal messages in forging representations. SRT suggests that the interaction between these messages and individual minds will play a strong role in framing people's behavioural choices. SRT studies can thereby indicate the types of messages that may encourage or undermine taking action against various risks.

Since SRT research shows that the network of concepts, images and associations that define a social representation are specific to certain groups, a one-sizefits-all communication strategy is unlikely to impact upon different sectors of a society in the same way. For example, the health sphere has seen much interest in the effectiveness of campaigns that recruit emotional responses such as disgust (and indeed surprise, humour and fear) to bring about change in health-related behaviours. A key contingency in such campaigns is that different groups respond differently to these emotively-tinged messages; for example, one study found that disgust-inducing messages significantly increased the practice of hand-washing in men but not in women (Judah et al., 2009). The take-home message is that tailoring risk messages to particular audiences is crucial. Such tailoring can only be achieved once the dynamics of each group's representation of a particular danger are understood. 
In terms of the broader context, contemporary societies appear to organise around a science of prediction, both in terms of predicting the dangers themselves and people's responses to them. Yet prediction is at its least possible regarding potential catastrophes. Unknowable risks hide behind a façade of calculability in the risk society (Beck, 2006). Stepping outside of the conventional conceptualisation of lay apprehension of potential danger as seen in mainstream risk perception research brings emotion and contemporary cultural thinking centre-stage. It is these facets of the response to potential danger, alongside more cognitive aspects of risk perception, that need to be understood in order to tackle the obdurate problem of low levels of preparatory behaviours in the face of risks.

\section{References}

Ajzen, I. (1991). The theory of planned behavior. Organizational Behavior and Human Decision Processes, 50(2), 179-211.

Bauer, M. W. (2009). The Evolution of Public Understanding of ScienceDiscourse and Comparative Evidence. Science Technology \& Society, 14(2), 221240.

Beck, U. (1992). Risk Society: Towards a New Modernity (M. Ritter, Trans.). London: Sage.

Beck, U. (1996). Risk society and the provident state. In S. Lash, B. Szerszynski \& B. Wynne (Eds.), Risk, Environment and Modernity: Towards a New Ecology (pp. 27-43). London: Sage.

Beck, U. (2006). Living in the world risk society. Economy and Society, 35(3), 329-345.

Bernstein, P.L. (1998). Against the Gods: The Remarkable Story of Risk. New York: John Wiley \& Sons.

Bish, A., \& Michie, S. (2010). Demographic and attitudinal determinants of protective behaviours during a pandemic: A review. British Journal of Health Psychology, 15(4), 797-824.

Douglas, M. (1992). Risk and Blame: Essays in Cultural Theory. London: Routledge.

Douglas, M., \& Wildavsky, A. (1982). Risk and Culture: An Essay on the Selection of Technical and Environmental Dangers. Berkeley: University of California Press.

Duveen, G. (2008). Social actors and social groups: a return to heterogeneity in social psychology. Journal for the Theory of Social Behaviour, 38, 369-374.

Epstein, S. (1994). Integration of the cognitive and the psychodynamic unconscious. American Psychologist, 49(8), 709-724.

Fishbein, M., \& Ajzen, I. (1975). Belief, Attitude, Intention, and Behavior: An Introduction to Theory and Research. Reading, MA: Addison-Wesley.

Fishbein, M., \& Cappella, J.N. (2006). The role of theory in developing effective health communications. Journal of Communication, 56, S1-S17. 
Graham, H. (1993). When Life's a Drag: Women, Smoking and Disadvantage. London: HMSO.

Hilgartner, S. (1990). The dominant view of popularisation: Conceptual problems, political uses. Social Studies of Science, 20(3), 519-539.

Höijer, B. (2010). Emotional anchoring and objectification in the media reporting on climate change. Public Understanding of Science, 19(6), 717-731.

Hollway, W., \& Jefferson, T. (2000). Doing Qualitative Research Differently: Free Association, Narrative and the Interview Method. London: Sage.

Hough, S. (2010). Predicting the Unpredictable: The Tumultuous Science of Earthquake Prediction. Princeton, NJ: Princeton University Press.

Joffe, H. (1996). AIDS research and prevention: A social representational approach. British Journal of Medical Psychology 69(3), 169-190.

Joffe, H. (1999). Risk and 'the Other'. Cambridge: Cambridge University Press.

Joffe, H. (2003). Risk: From perception to social representation. British Journal of Social Psychology, 42(1), 55-73.

Joffe, H. (2011). Public apprehension of emerging infectious diseases: Are changes afoot? Public Understanding of Science, 20(4), 446-460.

Joffe, H., \& Haarhoff, G. (2002). Representations of far-flung illnesses: the case of Ebola in Britain. Social Science \& Medicine, 54(6), 955-969.

Joffe, H., Rossetto, T., Bradley, C., \& O’Connor, C. (in preparation). Stigma in science: The case of earthquake prediction.

Joffe, H., Rossetto, T., Solberg, C., \& O’Connor, C. (in press). Social representations of earthquakes: A study of people living in three highly seismic areas. Earthquake Spectra.

Judah, G., Aunger, R., Schmidt, W.-P., Michie, S., Granger, S., \& Curtis, V. (2009). Experimental pretesting of hand-washing interventions in a natural setting. American Journal of Public Health, 99, 405-411.

Kahan, D.M., Jenkins-Smith, H. \& Braman, D. (2010). Cultural cognition of scientific consensus. Journal of Risk Research, 14, 147-174.

Leiserowitz, T. "Climate Change Risk Perception and Policy Preferences: The Role of Affect, Imagery and Values ". Climatic Change 77 (2006): 45-72.

Lerner JS, Gonzalez RM, Small DA \& Fischhoff, B. (2003). Effects of fear and anger on perceived risks of terrorism: A national field experiment. Psychological Science, 14 (2), 144-50.

Moscovici, S. (1984). The myth of the lonely paradigm: a rejoinder. Social Research, 51, 939-969.

Moscovici, S. (1988). Notes towards a description of social representations. European Journal of Social Psychology, 18, 211-250.

Moscovici, S. (1961/2008). Psychoanalysis: Its Image and Its Public. Cambridge: Polity Press. 
Nishikawa, S. (2011). Japan's preparedness and the great earthquake and tsunami. In Y. Funabashi \& H. Takenaka (eds.). Lessons from the disaster. (pp. 1747). Tokyo: The Japan Times.

Peters EM, Burraston B \& Mertz CK. (2004). An emotion-based model of risk perception and stigma susceptibility: Cognitive appraisals of emotion, affective reactivity, worldviews, and risk perceptions in the generation of technological stigma. Risk Analysis, 24(5), 1349-67.

Rossetto, T., Joffe, H., \& Solberg, C. (2011). A different view on human vulnerability to earthquakes: Lessons from risk perception studies. In R.J. Spence, E. So \& C. Scawthorn (Eds.), Human Casualties in Earthquakes: Progress in Modelling and Mitigation (pp. 291-304). Dordrecht, The Netherlands: Springer.

Rubin, G.J., Potts, H.W.W., \& Michie, S. (2010) The impact of communications about swine flu (influenza A H1N1v) on public responses to the outbreak: Results from 36 national telephone surveys in the UK. Health Technology Assessment, 14 (34), 183-266.

Sarewitz, D. (2010). World view: Tomorrow never knows. Nature, 463, 24.

Scoones, I., \& Foster, P. (2010). Unpacking the international response to avian influenza: Actors, networks and narratives. In I. Scoones (Ed), Avian Influenza, Science, Policy and Politics (pp. 19-64). London: Earthscan.

Sjoberg L. (2007). Emotions and risk perception. Risk Management, 9, 223-37.

Slovic, P. (Ed.)(2000). The Perception of Risk. London: Earthscan.

Slovic, P. (Ed.)(2010). The Feeling of Risk. London: Earthscan.

Slovic, P., Finucane, M. L., Peters, E., \& MacGregor, D. G. (2004). Risk as analysis and risk as feelings: Some thoughts about affect, reason, risk, and rationality. Risk Analysis, 24(2), 311-322.

Slovic, P., Peters, E., Finucane, M. L., \& MacGregor, D. G. (2005). Affect, risk, and decision making. Health Psychology, 24(4) Supplement, S35-S40.

Slovic, P., \& Peters, E. (2006). Risk perception and affect. Current Directions in Psychological Science, 15(6), 322-325.

Smith, N., \& Joffe, H. (in press). How the public engages with global warming: A social representations approach. Public Understanding of Science.

Smith, N., and A. Leiserowitz. "The Rise of Global Warming Scepticism:

Exploring Affective Image Associations in the United States over Time."

Risk Analysis 32 (2012): 1021-32.

Solberg, C., Rossetto, T., \& Joffe, H. (2010). The social psychology of seismic adjustment. Natural Hazards and Earth System Sciences, 10, 1663-1677.

Wagner, W., Duveen, G., Farr, R., Jovchelovitch, S., Lorenzi-Cioldi, F. \& Markova, I. (1999). Theory and method of social representations. Asian Journal of Social Psychology, 2, 95-125

Washer, P. (2004). Representations of SARS in the British newspapers. Social Science \& Medicine, 59(12), 2561-2571.

Washer, P. (2006). Representations of mad cow disease. Social Science \& Medicine, 62(2), 457-466. 
Washer, P., \& Joffe, H. (2006). The "hospital superbug": Social representations of MRSA. Social Science \& Medicine, 63(8), 2141-2152.

Washer, P., Joffe, H., \& Solberg, C. (2008). Audience readings of media messages about MRSA. Journal of Hospital Infection, 70(1), 42-47.

Weinstein, N.D. (1978). Cognitive processes and information seeking concerning an environmental health threat. Journal of Human Stress, 4, 32-41.

Weinstein, N. D. (2003). Exploring the links between risk perceptions and preventive health behavior. In J. Suls \& K. A. Wallston (Eds.), Social Psychological Foundations of Health and Illness (pp. 22-53). Oxford: Blackwell Publishing.

World Health Organisation (2012). The Great East Japan Earthquake: A Story of Devastating Natural Disaster, a Tale of Human Compassion. Geneva: WHO Press.

Yamori, K. (this volume). A historical overview of social representation of earthquake risk in Japan: Fatalism, social reform, scientific control and collaborative risk management. In H. Joffe, T. Rossetto \& J. Adams (Eds.), Cities at Risk: Living with Perils in the Twenty-First Century. Dordrecht, The Netherlands: Springer. 